\title{
COMPARISON OF BLOOD PRESSURE ACROSS BODY COMPOSITION AND CARDIORESPIRATORY FITNESS ZONES DETERMINED IN ACCORDANCE WITH FITNESSGRAM ${ }^{\circledR}$ CRITERION-REFERENCED STANDARDS
}

original paper

( $)$ University School of Physical Education in Wroclaw

DOI: https://doi.org/10.5114/hm.2020.89912

\section{GUSTAVO AIRES DE ARRUDA ${ }^{1}$, DIOGO HENRIQUE CONSTANTINO COLEDAM ${ }^{2}$, JOÃO PAULO DE AGUIAR GRECA ${ }^{3}$, MARCIO TEIXEIRA ${ }^{4,5}$, RAYMUNDO PIRES JÚNIOR $^{4,5}$, ARLI RAMOS DE OLIVEIRA ${ }^{4}$}

${ }^{1}$ University of Pernambuco, Recife, Brazil

${ }^{2}$ Federal Institute of Education, Science and Technology of São Paulo, Boituva, Brazil

${ }^{3}$ Brunel University London, Uxbridge, United Kingdom

${ }^{4}$ State University of Londrina, Londrina, Brazil

${ }^{5}$ Norte do Paraná University, Londrina, Brazil

\section{ABSTRACT}

Purpose. To compare systolic and diastolic blood pressures using the FitnessGram criterion-referenced standards for body composition and cardiorespiratory fitness in Brazilian young people.

Methods. The study had a cross-sectional design. With institutional approval, a sample of 874 students aged 13-18 years enrolled in public schools in a medium size town in Southern Brazil took part in this study. Body mass index was calculated to represent the subjects' body composition. The progressive aerobic cardiovascular endurance run (PACER) test was applied to estimate aerobic capacity. The participants were classified by using the FitnessGram criterion-referenced standards. Systolic and diastolic blood pressures were assessed with the oscillometric method.

Results. Multivariate analyses of covariance indicated that the blood pressure of boys (Wilks' lambda $=0.97, F(6,834)=2.48$, $p<0.05, E S=0.02$ ) and girls (Wilks' lambda $=0.94, F(6,886)=4.89, p<0.01, E S=0.03$ ) differed between fitness zones for body composition. The analyses showed that blood pressure also varied across cardiorespiratory fitness zones for girls (Wilks' lambda $=0.98, F(4,886)=2.69, p<0.05, E S=0.01$ ) but not for boys.

Conclusions. Reaching the health fitness zone of the criterion-referenced standards for body composition seems to be associated with lower blood pressure in boys and girls. Cardiorespiratory fitness had a similar effect solely in girls.

Key words: adolescents, physical fitness, aerobic, overweight, obesity, hypertension

\section{Introduction}

The incidence of risk factors for cardiovascular diseases, such as overweight or obesity, has increased in the last 3 decades among young people [1]. Other important risk factors, such as inappropriate cardiorespiratory fitness [2], have also been observed in a high proportion of individuals [3]. The FitnessGram program provides a battery of validated field-based fitness tests and health-related criterion-referenced (CR) standards, which have been used to help teachers track health-related fitness over time and to produce personalized reports for children, parents, and school administrators [4].

The available information on CR standards is based on samples from the USA [4-6], whereas evidence suggests that the ideal thresholds and diagnostic performance of any classification system could vary depending on the characteristics of the target population, such as age, ethnicity, socioeconomic status (SES), the outcome selected and its prevalence [7, 8]. Although FitnessGram CR standards are used in children and

Correspondence address: Gustavo Aires de Arruda, Universidade de Pernambuco, Faculdade de Enfermagem Nossa Senhora das Graças, Rua Arnóbio Marquês, nº310, Santo Amaro, CEP: 50.100-130, Recife, Pernambuco, Brazil, e-mail: arrudaga@yahoo.com.br

Received: September 27, 2018

Accepted for publication: October 3, 2019

Citation: Arruda GA, Coledam DHC, Greca JPA, Teixeira M, Pires Júnior R, Oliveira AR. Comparison of blood pressure

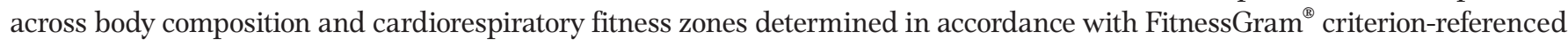
standards. Hum Mov. 2020;21(2):32-41; doi: https://doi.org/10.5114/hm.2020.89912. 
adolescents in Brazil, little is known about the capacity of these criteria as indicators of cardiovascular risk factors for this population.

The presence of cardiovascular disease risk factors or metabolic syndrome was selected as the primary outcome variable for determining appropriate cardiorespiratory fitness and body composition for FitnessGram CR standards. The applied risk factors included high values of blood pressure, high-density lipoprotein cholesterol, triglycerides, waist circumference, and fasting glucose $[5,6]$.

High blood pressure has been suggested as the leading risk factor for death globally. High blood pressure accounts for 9.4 million deaths worldwide annually, being responsible for $51 \%$ of deaths from stroke and at least $45 \%$ of deaths from heart disease [9]. It is relevant to consider that blood pressure values demonstrate stability from childhood to adulthood [10]. In addition, individuals with high systolic blood pressure present an increased risk of hypertension and metabolic syndrome later in life [11].

The capacity of the FitnessGram CR standards to identify participants with good health indicators is an important property $[4,5,11,12]$ to support their use in other countries. Valid, simple, and low-cost methods for screening would be useful to identify individuals at a high probability of presenting cardiovascular risk factors and to verify the effectiveness of intervention strategies. Therefore, the purpose of this study was to compare blood pressure values in Brazilian young people by using the FitnessGram CR standards for body composition and cardiorespiratory fitness.

\section{Methods}

\section{Design and participants}

The study had a cross-sectional design. The sample included adolescents from public schools of Londrina, Southern Brazil. According to the local department of education, 55,475 children and adolescents were enrolled in 2012 to grades from 6 in elementary schools to 3 in high schools in the public education sector of the city.

The selection of schools for data collection was randomized and data were gathered in 10 state schools: 3 schools from the North (boys: $n=139$, girls: $n=97$ ), 1 from the South (boys: $n=22$, girls: $n=33$ ), 2 from the East (boys: $n=43$, girls: $n=66$ ), 2 from the West (boys: $n=38$, girls: $n=30$ ), and 2 from the Central region (boys: $n=182$, girls: $n=224$ ). In each region, the schools were selected until proportionality was achieved and the necessary other school was chosen. The sample for the present study consisted of 424 boys and 450 girls.

\section{Systolic and diastolic blood pressure}

Blood pressure was assessed with an Omron HEM 742 device (Omron Healthcare, Kyoto, Japan). This device had been previously validated for this population [13]. Standard techniques of blood pressure determination were applied [14]. Prior to blood pressure assessment, the participants remained seated at rest for about 5 minutes. After this period, systolic (SBP) and diastolic (DBP) blood pressures were measured twice in the right arm of each subject, with an interval of 2 minutes between the measurements. The mean value of the 2 measurements was used for analysis.

\section{Anthropometric measurements}

Body mass was assessed by using Plenna ${ }^{\circledR}$ Acqua scales (Plenna Especialidades Ltda, São Paulo, Brazil) with a precision of $100 \mathrm{~g}$. Stature was assessed with a portable stadiometer with a precision of $0.1 \mathrm{~cm}$. Body mass index (BMI) was calculated by dividing body mass $(\mathrm{kg})$ by the squared height $(\mathrm{m})$.

\section{Cardiorespiratory fitness}

The progressive aerobic cardiovascular endurance run (PACER) fitness test served to assess cardiorespiratory fitness [4]. The tests were carried out in an indoor court, in the morning (8:00-11:50 a.m.) and afternoon (1:30-5:20 p.m.). Before the beginning of the test, all procedures were explained to the students, along with a demonstration of the test given by a researcher. The subjects had the opportunity to familiarize themselves with the starting speed of the test. Each participant received an identification control number. One member of the group received a form (with details such as name and identification number) to mark the number of laps performed by particular individuals. There was an evaluator for each 5 adolescents, responsible for overseeing the marked routes, and an evaluator at each end of the pathway, responsible for checking possible delays and providing guidance on the rate of displacement. The participants were evaluated in groups of approximately 15 . Maximum oxygen uptake $\left(\mathrm{VO}_{2} \max \right)$ was estimated by using the equation proposed by Burns et al. [15]. 


\section{Criterion-referenced standards}

The classification depending on BMI was the following: very lean (VL), health fitness zone (HFZ), needs improvement: some risk (NI-SR), and needs improvement: high risk (NI-HR). The classification depending on $\mathrm{VO}_{2}$ max was the following: HFZ, NI-SR, and NI-HR, on the basis of the FitnessGram CR standards [4]. BMI information was subsequently dichotomized into HFZ $(\mathrm{VL}+\mathrm{HFZ})$ and NI (NI-SR + NI-HR), and $\mathrm{VO}_{2} \max$ information was also dichotomized into HFZ and NI (NI-SR + NI-HR). Data regarding BMI and $\mathrm{VO}_{2} \max$ were combined and groups were classified as HFZ/ HFZ, HFZ/NI, NI/HFZ, and NI/NI.

\section{Socioeconomic status}

The guidelines proposed by the Brazilian Market Research Association [16] were used to classify the SES of families. In this questionnaire, the answers are converted into scores (continuous variable) with a point system, and the results divide the Brazilian population into economic classes depending on their spending power. The criteria result in 8 categories (A1, A2, B1, B2, C1, C2, D, and E), from A1 to E, in descending order of spending power.

\section{Statistical analysis}

The Kolmogorov-Smirnov test was used to verify the normality of the variable distribution. Central tendency and dispersion (mean and standard deviation) measures, relative frequency (\%), and 95\% confidence interval (CI) were applied for sample characterization. The Student's unpaired $t$-test served to compare the characteristics between boys and girls. The Levene's test assessed the equality of variances. In separated multivariate analyses of covariance (MANCOVAs) for boys and girls, blood pressure (SBP and DBP) was compared between body composition (BMI) fitness zones, with age and SES score (continuous variable) as covariates. The same procedure was implemented with cardiorespiratory fitness as a factor, and partial eta squared $\left(\mathrm{h}_{\mathrm{p}}{ }^{2}\right)$ were presented as a measure of effect size (ES). The $E S$ was interpreted as recommended by Richardson [17], with the range of 0.01-0.05 standing for small ES, 0.06-0.13 for medium $E S$, and $\geqslant 0.14$ for large ES. The Box's M test verified the assumption of homogeneity of the covariance matrices (the value of significance was set at $p<$ 0.01). The Pearson correlation was used to verify the correlation between dependent variables. Follow-up analyses of covariance (ANCOVAs) were conducted to determine which variables most clearly differed between the levels of body composition and cardiorespiratory fitness, and $\mathrm{h}_{\mathrm{p}}{ }^{2}$ was presented. Discriminant function analysis (DFA) was used to check the contribution of each variable to the differences between body composition and cardiorespiratory fitness zones. Group centroids for synthetic composite for blood pressure were compared with age, SES, and sex score as covariates by using ANCOVAs. The value of significance was set at $p<0.05$. All analyses were performed with the IBM Statistical Package for the Social Sciences, version 20 (Somers, USA).

\section{Ethical approval}

The research related to human use has complied with all the relevant national regulations and institutional policies, has followed the tenets of the Declaration of Helsinki, and has been approved by the Ethics in Research Committee of the State University of Londrina / University Hospital of Northern Paraná (\#312/2011).

\section{Informed consent}

Informed consent has been obtained from the parents or legal guardians of all individuals included in this study. The consent form described all procedures, researcher contact details, and possible risks and benefits of the study.

\section{Results}

The characteristics of the participants are presented in Table 1. The MANCOVA results are described in the text. All $p$ values for Box's M test were $>0.01$ and interpreted as non-significant. Figure 1 and Tables 2-4 show the comparison of blood pressure values when body composition and cardiorespiratory fitness CR standards are used as factors for ANCOVAs. All assumptions were met with $p$ values being higher than 0.05 .

Boys presented significantly higher body mass, height, $\mathrm{SBP}, \mathrm{VO}_{2} \mathrm{max}$, and PACER laps than girls. Age, BMI, and DBP did not differ significantly between genders (Table 1). The SES obtained for boys in the study were the following: A1: $0.5 \%$, A2: $17.2 \%, \mathrm{~B} 1: 16.5 \%$, B2: $19.3 \%, \mathrm{C} 1: 19.6 \%$, C2: $20.0 \%$, D: $6.8 \%$, and E: $0.0 \%$. For girls, the values were as follows: A1: $0.9 \%$, A2: 22.5\%, B1: 20.7\%, B2: 15.1\%, C1: 17.1\%, C2: 13.4\%, D: $10.0 \%$, and E: $0.2 \%$. Classification into the the HFZ group in body composition was $74.3 \%$ (95\% CI: 70.1; 78.5 ) for boys and $81.3 \%$ (95\% CI: 77.8 ; 84.9) for 
Table 1. Characteristics of the sample

\begin{tabular}{lccrrr}
\hline Characteristics & Boys $(n=424)$ & Girls $(n=450)$ & $d f$ & \multicolumn{1}{c}{$t$} & \multicolumn{1}{c}{$p$} \\
\hline Age (years) & $15.4(1.5)$ & $15.4(1.6)$ & 872 & -0.36 & 0.719 \\
Body mass (kg) & $61.7(14.0)$ & $54.4(10.8)$ & 795 & 8.65 & $<0.001$ \\
Height $(\mathrm{cm})$ & $170.4(9.3)$ & $161.4(6.4)$ & 741 & 16.59 & $<0.001$ \\
$\mathrm{BMI}\left(\mathrm{kg} / \mathrm{m}^{2}\right)$ & $21.1(3.8)$ & $20.8(3.6)$ & 872 & 1.14 & 0.254 \\
$\mathrm{SBP}(\mathrm{mm} \mathrm{Hg})$ & $118.9(12.9)$ & $111.9(10.6)$ & 819 & 8.77 & $<0.001$ \\
$\mathrm{DBP}(\mathrm{mm} \mathrm{Hg})$ & $64.0(9.0)$ & $64.6(7.5)$ & 824 & -1.04 & 0.297 \\
$\mathrm{VO}_{2}$ max $(\mathrm{ml} / \mathrm{kg} / \mathrm{min})^{*}$ & $43.2(6.3)$ & $36.2(4.2)$ & 729 & 19.24 & $<0.001$ \\
${\text { PACER }(\mathrm{laps})^{*}}_{\text {SES (score) }}^{41.9(18.3)}$ & $22.3(10.7)$ & 676 & 19.24 & $<0.001$ \\
\hline
\end{tabular}

Values expressed as mean (standard deviation).

* One missing value for girls $(n=449)$

BMI - body mass index, SBP - systolic blood pressure, DBP - diastolic blood pressure, $\mathrm{VO}_{2} \mathrm{max}$ - maximum oxygen uptake, PACER - progressive aerobic cardiovascular endurance run, SES - socioeconomic status

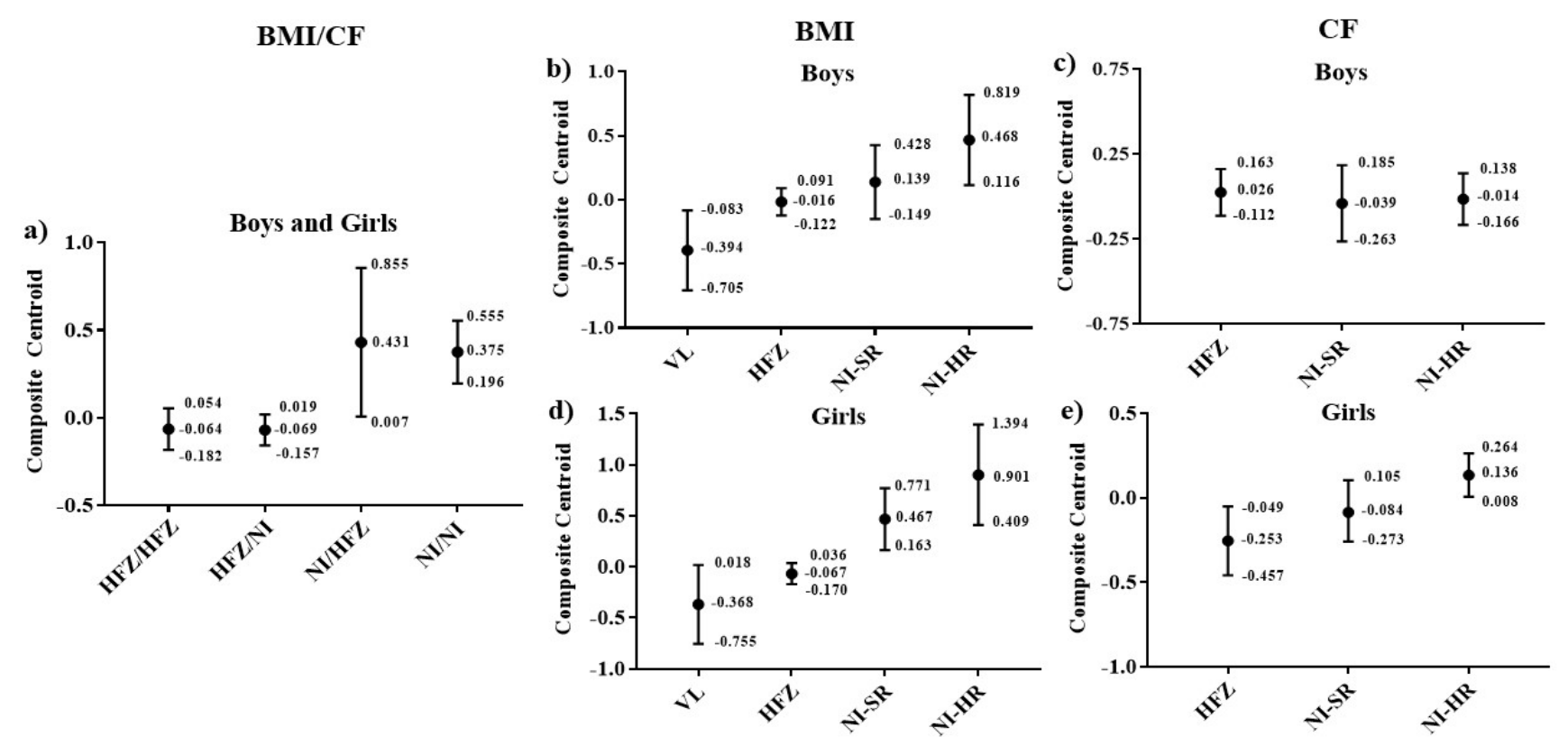

BMI - body mass index, CF - cardiorespiratory fitness

Figure 1a: HFZ - health fitness zone (VL + HFZ), $\mathrm{NI}$ - needs improvement ( $\mathrm{NI}-\mathrm{SR}+\mathrm{NI}-\mathrm{HR}$ )

Figure 1b-e: VL - very lean, HFZ - health fitness zone, NI-SR - needs improvement: some risk, NI-HR - needs improvement: high risk

Figure 1. Comparison between group centroids for synthetic composite for blood pressure with BMI/CF criterion-referenced standards as a factor and controlled for age, socioeconomic status, and sex by using ANCOVAs.

Values are expressed as estimated mean (95\% confidence interval)

girls, and that for cardiorespiratory fitness was $45.5 \%$ (95\% CI: 40.8; 50.3) for boys and 21.1\% (95\% CI: 17.4; 24.9) for girls. The Pearson correlation (continuous data) showed that there was a moderate relationship between the dependent variables (SBP and DBP) for boys ( $r=0.50$; 95\% CI: $0.43 ; 0.57)$ and girls $(r=0.65$; 95\% CI: 0.59; 0.70).

Participants classified as HFZ/HFZ for BMI and cardiorespiratory fitness had the composite centroid for blood pressure significantly lower than those classified as NI/NI. This difference was observed even when the criteria for cardiorespiratory fitness were not achieved (Figure 1a). In boys, BMI in the VL and HFZ groups had lower centroid composites as compared with NI-HR (Figure 1b). In girls, VL and HFZ groups had values lower than NI-SR and NI-HR (Figure 1d). Cardiorespiratory fitness differences were revealed between HFZ and NI-HR, but only in girls (Figure 1e).

MANCOVA showed that blood pressure values were significantly affected by the BMI and cardiorespiratory fitness zones (Wilks' lambda $=0.97, F(6,1730)=$ 4.75, $p<0.01, E S=0.02)$. The covariate of age (Wilks' 
lambda $=0.98, F(2,865)=10.92, p<0.01, E S=0.03)$, as well as SES (Wilks' lambda $=0.98, F(2,865)=$ 10.43, $p<0.01, E S=0.02$ ) and sex (Wilks' lambda $=$ $0.88, F(2,865)=59.89, p<0.01, E S=0.12)$ significantly influenced the dependent variables as a group. DFA for BMI and cardiorespiratory fitness zones had a canonical correlation of 0.31 , the structural coefficients obtained in DFA revealed that sex (0.86) and age (0.47) contributed most to discriminant differences for BMI and cardiorespiratory fitness classification in relation to SBP (-0.26), SES (-0.12), and DBP (0.08). Follow-up ANCOVA adjusted for age, SES, and sex showed that $\operatorname{SBP}(F(3,866)=8.01, p<0.01, E S=0.03)$ and $\operatorname{DBP}(F(3,866)=5.43, p<0.01, E S=0.02)$ were also significantly different between the BMI and cardiorespiratory fitness zones. The covariate of age significantly affected SBP and DBP $(p<0.01)$, SES significantly affected only DBP $(p<0.01)$, and sex affected SBP $(p<0.01)$ (Table 2).

For boys, the MANCOVA revealed that blood pressure values were significantly affected by the BMI zones (Wilks' lambda $=0.97, F(6,834)=2.48, p<0.05$, $E S=0.02)$. The covariate of age (Wilks' lambda $=0.91$, $F(2,417)=20.85, p<0.01, E S=0.09)$, as well as SES (Wilks' lambda $=0.97, F(2,417)=6.61, p<0.01, E S=$ $0.03)$ significantly influenced the dependent variables as a group. DFA for BMI zones had a canonical correlation of 0.18 , the structural coefficients obtained in DFA revealed that SBP $(0.81)$ and DBP $(0.80)$ contributed most to discriminant differences for BMI classification in relation to SES $(-0.13)$ and age $(-0.03)$ for boys. Follow-up ANCOVA adjusted for age and SES showed that $\operatorname{SBP}(F(3,418)=3.62, p<0.05, E S=$ $0.03)$ and DBP $(F(3,418)=3.45, p<0.05, E S=0.02)$ were also significantly different between the BMI zones. The covariate of age significantly affected SBP and DBP $(p<0.01)$, and SES significantly impacted only on DBP $(p<0.01)$ (Table 3$)$.

For girls, the MANCOVA proved that blood pressure values were significantly affected by BMI zones (Wilks' lambda $=0.94, F(6,886)=4.89, p<0.01, E S=$ 0.03 ). The covariate of age (Wilks' lambda $=0.98$, $F(2,443)=4.88, p<0.01, E S=0.02)$, as well as SES (Wilks' lambda $=0.98, F(2,443)=4.12, p<0.05$, $E S=0.02)$ significantly influenced the dependent variables as a group. DFA indicated a canonical correlation of 0.24 for BMI, the structural coefficients obtained for girls revealed that SBP $(0.97)$ and DBP $(0.74)$ contributed most to BMI discriminant differences in classification in relation to SES (-0.19) and age (0.02). The follow-up ANCOVA adjusted for age and SES revealed that differences in $\operatorname{SBP}(F(3,444)=8.75, p<0.01$,
$E S=0.06)$ and $\operatorname{DBP}(F(3,444)=5.39, p<0.01, E S=$ 0.04 ) also occurred separately between the BMI zones. Age did not significantly affect SBP but did significantly affect DBP $(p<0.05)$, and SES did not significantly impact on SBP or DBP (Table 3).

For boys, the MANCOVA showed that the blood pressure values were not significantly affected by the cardiorespiratory fitness zones (Wilks' lambda $=0.99$, $F(4,836)=0.19, p>0.05, E S=0.00)$. The covariate of age (Wilks' lambda $=0.91, F(2,418)=20.28, p<0.01$, $E S=0.09$ ), as well as SES (Wilks' lambda $=0.97, F$ $(2,418)=6.51, p<0.01, E S=0.03)$ significantly influenced the dependent variables as a group. DFA indicated a canonical correlation of 0.19 for cardiorespiratory fitness zones for boys, the structural coefficients obtained revealed that SBP (0.98) contributed most to cardiorespiratory fitness discriminant differences in classification in relation to DBP (0.19), age (0.11), and SES (-0.15). The follow-up ANCOVA adjusted for age and SES proved that SBP and DBP were not significantly different between the cardiorespiratory fitness zones. Age significantly affected SBP $(p<$ $0.01)$ and DBP $(p<0.01)$, and SES did not influence SBP but did significantly impact on DBP $(p<0.01)$ (Table 4).

For girls, the MANCOVA revealed that blood pressure values were significantly affected by cardiorespiratory fitness zones (Wilks' lambda $=0.98, F(4,886)$ $=2.69, p<0.05, E S=0.01)$. The covariate of age (Wilks' lambda $=0.98, F(2,443)=2.74, p>0.05, E S=0.01)$ did not significantly influence variables as a group but SES (Wilks' lambda $=0.98, F(2,443)=4.09, p<$ $0.05, E S=0.02)$ did. DFA indicated a canonical correlation of 0.33 for cardiorespiratory fitness zones, the structural coefficients obtained suggest that SES (0.83) and DBP (-0.47) contributed most to cardiorespiratory fitness discriminant differences in classification in relation to age (0.27) and SBP $(-0.13)$. The follow-up ANCOVA adjusted for age and SES proved that for separate analyses, just differences in DBP $(p<$ 0.01 ) occurred between cardiorespiratory fitness zones. The covariates of age and SES did not significantly impact on the blood pressure values (Table 4).

\section{Discussion}

The present study sought to compare SBP and DBP by using the FitnessGram CR standards for body composition and cardiorespiratory fitness in Brazilian young people. The most important information obtained in the study is that participants in the HFZ group for BMI presented significantly lower blood pres- 
Table 2. Comparison of blood pressure with BMI/CF CR standards as a factor and controlled for age, SES, and sex by using ANCOVAs

\begin{tabular}{|c|c|c|c|c|c|c|c|c|c|c|}
\hline & \multicolumn{2}{|c|}{ HFZ/HFZ $(n=268)$} & \multicolumn{2}{|c|}{ HFZ/NI $(n=475)$} & \multicolumn{3}{|c|}{ NI/HFZ $(n=20)$} & $\mathrm{NI} / \mathrm{NI}(n=110)$ & $F$ & $E S$ \\
\hline SBP & \multicolumn{2}{|c|}{$\begin{array}{c}114.6 \\
(113.2 ; 116.0)\end{array}$} & \multicolumn{2}{|c|}{$\begin{array}{c}114.5 \\
(113.5 ; 115.6) \\
\end{array}$} & \multicolumn{3}{|c|}{$\begin{array}{c}120.6 \\
(115.6 ; 125.7)\end{array}$} & $\begin{array}{c}119.7 \\
(117.6 ; 121.9)\end{array}$ & $8.01 *$ & 0.03 \\
\hline \multirow[t]{3}{*}{ DBP } & $\begin{array}{c}63.8 \\
(62.8 ; 64 .\end{array}$ & & $\begin{array}{r}63.9 \\
(63.2 ; 6\end{array}$ & & & $\begin{array}{c}64.9 \\
51.3 ; 68.5)\end{array}$ & & $\begin{array}{c}67.2 \\
(65.7 ; 68.7)\end{array}$ & $5.43 *$ & 0.02 \\
\hline & \multicolumn{3}{|c|}{ Age } & \multicolumn{4}{|c|}{ SES } & \multicolumn{3}{|c|}{ Sex } \\
\hline & $\beta(95 \% \mathrm{CI})$ & $F$ & $E S$ & $\beta(95$ & & $\mathrm{F}$ & ES & $\beta(95 \% \mathrm{CI})$ & $F$ & ES \\
\hline SBP & $\begin{array}{c}1.09 \\
(0.60 ; 1.58)\end{array}$ & $19.39 *$ & 0.02 & $\begin{array}{r}-0 \\
(-0.12\end{array}$ & .06) & 0.36 & 0.00 & $\begin{array}{c}6.80 \\
(-8.39 ;-5.21)\end{array}$ & $70.39^{*}$ & 0.08 \\
\hline DBP & $\begin{array}{c}0.65 \\
(0.31 ; 1.00)\end{array}$ & $13.90^{*}$ & 0.02 & $\begin{array}{r}0 . \\
(0.05\end{array}$ & & $11.98^{*}$ & 0.01 & $\begin{array}{c}0.74 \\
(-0.38 ; 1.87)\end{array}$ & 1.67 & 0.00 \\
\hline
\end{tabular}

Values expressed as estimated mean $(95 \% \mathrm{CI})$.

${ }^{*} p<0.01$

BMI - body mass index, CF - cardiorespiratory fitness, CR - criterion-referenced, SES - socioeconomic status,

HFZ - health fitness zone, NI - needs improvement, SBP - systolic blood pressure, DBP - diastolic blood pressure,

$E S$ - effect size, CI - confidence interval

Table 3. Comparison of blood pressure with BMI CR standards as a factor and controlled for age and SES for boys and girls by using ANCOVAs

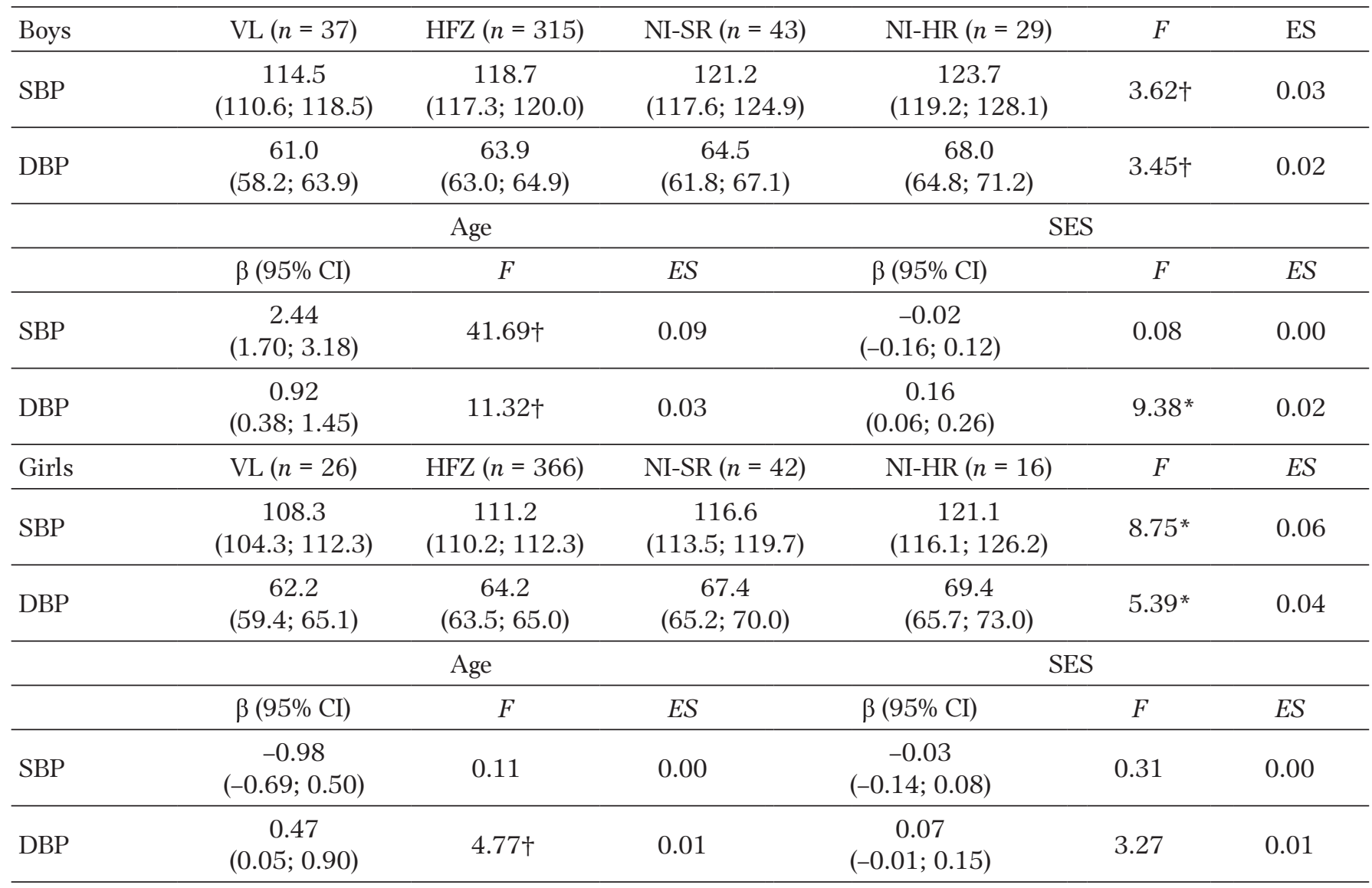

Values expressed as estimated mean $(95 \% \mathrm{CI})$.

${ }^{*} p<0.01, \dagger p<0.05$

BMI - body mass index, CR - criterion-referenced, VL - very lean, HFZ - health fitness zone, NI-SR - needs improvement: some risk, NI-HR - needs improvement: high risk, ES - effect size, SES - socioeconomic status, SBP - systolic blood pressure, DBP - diastolic blood pressure, CI - confidence interval 


\section{HUMAN MOVEMENT}

G. Arruda et al., FitnessGram health-related criteria

Table 4. Comparison of blood pressure with cardiorespiratory fitness CR standards as a factor and controlled for age and SES for boys and girls by using ANCOVAs

\begin{tabular}{|c|c|c|c|c|c|c|}
\hline Boys & $\operatorname{HFZ}(n=193)$ & \multicolumn{2}{|c|}{ NI-SR $(n=72)$} & NI-HR $(n=159)$ & $F$ & $E S$ \\
\hline SBP & $\begin{array}{c}119.2 \\
(117.4 ; 120.9)\end{array}$ & \multicolumn{2}{|c|}{$\begin{array}{c}119.0 \\
(116.1 ; 121.8)\end{array}$} & $\begin{array}{c}119.0 \\
(116.7 ; 120.5)\end{array}$ & 0.09 & 0.00 \\
\hline \multirow[t]{3}{*}{ DBP } & $\begin{array}{c}64.2 \\
(63.0 ; 65.5)\end{array}$ & \multicolumn{2}{|c|}{$\begin{array}{c}63.4 \\
(61.3 ; 65.4)\end{array}$} & $\begin{array}{c}64.0 \\
(62.6 ; 65.4)\end{array}$ & 0.25 & 0.01 \\
\hline & \multicolumn{3}{|c|}{ Age } & \multicolumn{3}{|c|}{ SES } \\
\hline & $\beta(95 \% \mathrm{CI})$ & $F$ & $E S$ & $\beta(95 \% \mathrm{CI})$ & $F$ & $E S$ \\
\hline SBP & $\begin{array}{c}2.48 \\
(1.71 ; 3.24)\end{array}$ & $40.62^{*}$ & 0.09 & $\begin{array}{c}-0.03 \\
(-0.17 ; 0.12)\end{array}$ & 0.13 & 0.00 \\
\hline DBP & $\begin{array}{c}0.91 \\
(0.36 ; 1.46)\end{array}$ & $10.57^{*}$ & 0.03 & $\begin{array}{c}0.16 \\
(0.05 ; 0.26)\end{array}$ & $8.79^{*}$ & 0.02 \\
\hline Girls & $\operatorname{HFZ}(n=95)$ & \multicolumn{2}{|c|}{ NI-SR $(n=110)$} & NI-HR $(n=224)$ & $F$ & $E S$ \\
\hline SBP & $\begin{array}{c}110.2 \\
(108.1 ; 112.4)\end{array}$ & \multicolumn{2}{|c|}{$\begin{array}{c}111.6 \\
(109.6 ; 113.6)\end{array}$} & $\begin{array}{c}112.8 \\
(111.4 ; 114.1)\end{array}$ & 1.89 & 0.01 \\
\hline \multirow[t]{3}{*}{ DBP } & $\begin{array}{c}62.7 \\
(61.2 ; 64.2)\end{array}$ & \multicolumn{2}{|c|}{$\begin{array}{c}64.0 \\
(62.6 ; 65.4)\end{array}$} & $\begin{array}{c}65.6 \\
(64.7 ; 66.6)\end{array}$ & $5.37^{*}$ & 0.02 \\
\hline & \multicolumn{3}{|c|}{ Age } & \multicolumn{3}{|c|}{ SES } \\
\hline & $\beta(95 \% \mathrm{CI})$ & $F$ & ES & $\beta(95 \% \mathrm{CI})$ & $F$ & $E S$ \\
\hline SBP & $\begin{array}{c}-0.28 \\
(-0.92 ; 0.35)\end{array}$ & 0.77 & 0.00 & $\begin{array}{c}-0.05 \\
(-0.16 ; 0.07)\end{array}$ & 0.67 & 0.00 \\
\hline DBP & $\begin{array}{c}0.25 \\
(-0.20 ; 0.69)\end{array}$ & 1.17 & 0.00 & $\begin{array}{c}0.06 \\
(-0.02 ; 0.14)\end{array}$ & 2.43 & 0.01 \\
\hline
\end{tabular}

Values expressed as estimated mean $(95 \% \mathrm{CI})$.

${ }^{*} p<0.01$

CR - criterion-referenced, HFZ - health fitness zone, NI-SR - needs improvement: some risk, NI-HR - needs improvement: high risk, ES - effect size, SES - socioeconomic status, SBP - systolic blood pressure, DBP - diastolic blood pressure,

CI - confidence interval

sure values when compared with those in the NI groups. Additionally, SES and age seem to be important variables when analysing these differences. For cardiorespiratory fitness, this effect was verified just for girls. DFA and ANCOVA suggested that DBP was more influenced by cardiorespiratory fitness than SBP. Although significant differences for blood pressure were found by applying the CR standards for BMI in both sexes, the $E S$ values were small. The comparison between composite centroid and SBP in girls yielded a medium $E S$. CR standards for cardiorespiratory fitness showed difference only in DBP in girls, but the ES was small.

The ideal thresholds and diagnostic performance of any classification system can vary depending on the characteristics of the target population, such as age, ethnicity, SES, and the selected outcome and its prevalence $[7,8]$. SES has been suggested as a factor associated with physical fitness [18], as well as potentially being an important covariate for investigations into physical fitness and cardiovascular disease associations [19].

The blood pressure values differ significantly between fitness zones for body composition, even when adjusted for age and SES. The structural coefficients obtained from DFA indicated that the blood pressure values had the highest contributions to the discrimination of fitness zones and that SES had a greater contribution than age. The effect of these covariates appears to be different when blood pressure values are analysed separately. In ANCOVA analyses, SES was identified as a significant covariate only for boys in the comparisons of DBP $(\beta=0.16$; $95 \% \mathrm{CI}$ : 0.06 ; 0.26 ; $p<0.01$ ), but age was a significant covariate for boys $(\beta=0.92 ; 95 \%$ CI: $0.38 ; 1.45 ; p<0.05)$ and girls $(\beta=$ 
0.47; 95\% CI: 0.05; 0.90; $p<0.05$ ). For SBP, age was a significant covariate just for boys $(\beta=2.44 ; 95 \% \mathrm{CI}$ : $1.70 ; 3.18 ; p<0.05)$. Higher values of age and SES were related to higher blood pressure values. For cardiorespiratory fitness, no significant differences were revealed between groups. However, similar results in relation to covariates were verified.

The difference in blood pressure values observed in this cross-sectional study seems modest. However, even a small improvement in blood pressure values seems to have a profound impact on population health. As reported by Lewington et al. [20], a reduction of $2 \mathrm{~mm} \mathrm{Hg}$ in DBP decreases the prevalence of hypertension by $17 \%$ and reduces the risk of coronary heart disease and stroke by $6 \%$ and $15 \%$, respectively; similar results have been found in other studies. These evidence supports the clinical significance of the results presented in this study [21]. For example, comparisons with significant values for ANCOVA show mean differences between HFZ and NI-SR that range from $0.6 \mathrm{~mm} \mathrm{Hg}$ (boys) to $3.2 \mathrm{~mm} \mathrm{Hg}$ (girls) for DBP and from $2.5 \mathrm{~mm} \mathrm{Hg}$ (boys) to $5.4 \mathrm{~mm} \mathrm{Hg}$ (girls) for SBP.

Blood pressure values appear to demonstrate stability from childhood to adulthood [10] and individuals with high SBP present an increased risk of hypertension and metabolic syndrome later in life [11]. Cardiorespiratory fitness and body composition seem to be associated with a healthy cardiovascular profile $[22,23]$ and to maintain moderate stability from childhood to adulthood [24-26].

High cardiorespiratory fitness and lower adiposity indicators have independent beneficial effects on cardiovascular risk factors in children and adolescents [2] and could be relevant parameters for screening subjects most likely to present cardiovascular risk factors. The present study found that $54.5 \%$ of boys and $78.9 \%$ of girls did not meet the CR standards for cardiorespiratory fitness, and $16.9 \%$ of boys and $12.9 \%$ of girls were in the NI zone for BMI, which indicates an increased likelihood of presenting cardiovascular risk factors for these participants.

The higher blood pressure values obtained in the NI groups for BMI in the present study corroborate the information that suggests that youth in the NI-SR or NI-HR groups were more likely to have poor metabolic profile (metabolic syndrome) than those in the normal-weight or HFZ groups [8, 27]. In the studies by Laurson et al. [8, 27], other cardiovascular risk factors were analysed in addition to blood pressure. Although FitnessGram CR standards were developed by using metabolic syndrome as outcome, the analysis of high blood pressure is relevant as high blood pressure is indicated as the leading risk factor for death globally [9].

Franks et al. [28] investigated 4857 children with a mean age of 11.3 years who were followed for an average period of 24 years. The authors found that the presence of hypertension in childhood was significantly associated with premature mortality from endogenous causes, with an incidence ratio of 1.57 (95\% CI: 1.10; 2.24). Programs that successfully result in reduction in BMI status for their age group, in children, may have important beneficial effects on subsequent blood pressure [29]. Overall, the present study indicated that individuals classified in the NI zone for BMI presented poor blood pressure profiles and the same occurred for cardiorespiratory fitness in girls. The identification of young people who do not meet these CR standards may help to recognize the target population and develop prevention strategies for paediatric chronic degenerative diseases.

The present study has limitations that must be taken into account. Firstly, owing to the cross-sectional nature of the study design, causal inferences cannot be made. Also, other covariates which could influence the association between cardiorespiratory fitness and BMI with blood pressure values, such as physical activity and eating habits, were not verified. Furthermore, blood pressure was assessed on a single day, which may have resulted in an overestimate of high blood pressure prevalence. However, this is a common limitation in epidemiological studies. Although a direct assessment of body fatness for screening has advantages when compared with the use of BMI, which is unable to discern fat mass from fat-free mass [30], the use of BMI is very common in schools, as well as in clinical practice. An important characteristic of the FitnessGram CR standards for BMI is that it is linked to health risks on the basis of corresponding risks for body fatness. These CR standards demonstrate a reasonable agreement when used to classify adiposity status in children and adolescents [5].

Further studies investigating Brazilian young people should consider analysing cardiovascular risk factors beyond blood pressure, such as waist circumference, triglycerides, high-density lipoprotein cholesterol, and fasting glucose. These variables were used in the development of the FitnessGram CR standards [6, 8, 12]. Also, other risk factors that could provide additional information about the relationship between CR standards zones and health profile include C-reactive protein [7]. The agreement of results for alternative tests for body composition and cardiorespiratory fitness is another relevant aspect to investigate. 


\section{Conclusions}

Reaching the HFZ for CR standards seems to indicate a better profile of blood pressure. Classification in the NI zone for body composition was connected with higher blood pressure values; however, for cardiorespiratory fitness, this effect occurred only for girls. These findings suggest the necessity for developing CR standards for cardiorespiratory fitness based in Brazilian boys. Since physical fitness seems to track from childhood to adulthood and is associated with cardiovascular risk factors, findings from the present study provide support for the use of the CR standards of FitnessGram to interpret information about body composition and cardiorespiratory fitness in Brazilian young people. To the best of our knowledge, no study has previously investigated the use of CR standards in Brazilian young people.

The CR standards for physical fitness could be applied by school teachers during physical education classes or in physical activity groups in order to advise young people about their condition of physical fitness, as well as inform parents and guardians. The CR standards could also possibly be used to analyse the effectiveness of physical activity programs and other public health promotion policies for Brazilian young people.

\section{Disclosure statement}

No author has any financial interest or received any financial benefit from this research.

\section{Conflict of interest}

The authors state no conflict of interest.

\section{References}

1. Ng M, Fleming T, Robinson M, Thomson B, Graetz N, Margono C, et al. Global, regional, and national prevalence of overweight and obesity in children and adults during 1980-2013: a systematic analysis for the Global Burden of Disease Study 2013. Lancet. 2014;384(9945): 766-781; doi: 10.1016/S0140-6736(14)60460-8.

2. Jago R, Froberg K, Cooper AR, Eiberg S, Andersen LB. Three-year changes in fitness and adiposity are independently associated with cardiovascular risk factors among young Danish children. J Phys Act Health. 2010; 7(1):37-44; doi: 10.1123/jpah.7.1.37.

3. Clark BR, Uhrich ML, Dill TC, White ML, Milam L, Ackermann N, et al. Failure to meet aerobic fitness standards among urban elementary students. Prev Med Rep. 2018;12:330-335; doi: 10.1016/j.pmedr.2018.10.011.

4. The Cooper Institute. FitnessGram administration manual: the journey to MyHealthyZone, $5^{\text {th }} \mathrm{ed}$. Champaign: Human Kinetics; 2017.
5. Laurson KR, Eisenmann JC, Welk GJ. Body mass index standards based on agreement with health-related body fat. Am J Prev Med. 2011;41(4 Suppl. 2):S100S105; doi: 10.1016/j.amepre.2011.07.004.

6. Welk GJ, Laurson KR, Eisenmann JC, Cureton KJ. Development of youth aerobic-capacity standards using receiver operating characteristic curves. Am J Prev Med. 2011;41(4 Suppl. 2):S111-S116; doi: 10.1016/j.amepre.2011.07.007.

7. Going SB, Lohman TG, Cussler EC, Williams DP, Morrison JA, Horn PS. Percent body fat and chronic disease risk factors in U.S. children and youth. Am J Prev Med. 2011;41(4 Suppl. 2):S77-S86; doi: 10.1016/j.amepre.2011.07.006.

8. Laurson KR, Welk GJ, Eisenmann JC. Diagnostic performance of BMI percentiles to identify adolescents with metabolic syndrome. Pediatrics. 2014;133(2):e330-e338; doi: 10.1542/peds.2013-1308.

9. Lim SS, Vos T, Flaxman AD, Danaei G, Shibuya K, Adair-Rohani H, et al. A comparative risk assessment of burden of disease and injury attributable to 67 risk factors and risk factor clusters in 21 regions, 19902010: a systematic analysis for the Global Burden of Disease Study 2010. Lancet. 2012;380(9859):22242260; doi: 10.1016/S0140-6736(12)61766-8.

10. Lee MH, Kang DR, Kim HC, Ahn SV, Khaw K-T, Suh I. A 24-year follow-up study of blood pressure tracking from childhood to adulthood in Korea: the Kangwha Study. Yonsei Med J. 2014;55(2):360-366; doi: 10.3349/ymj.2014.55.2.360.

11. Sun SS, Grave GD, Siervogel RM, Pickoff AA, Arslanian SS, Daniels SR. Systolic blood pressure in childhood predicts hypertension and metabolic syndrome later in life. Pediatrics. 2007;119(2):237-246; doi: 10.1542/peds.2006-2543.

12. Welk GJ, De Saint-Maurice Maduro PF, Laurson KR, Brown DD. Field evaluation of the new FITNESSGRAM ${ }^{\circledR}$ criterion-referenced standards. Am J Prev Med. 2011; 41(4 Suppl. 2):S131-S142; doi: 10.1016/j.amepre.2011. 07.011.

13. Christofaro DG, Casonatto J, Polito MD, Cardoso JR, Fernandes R, Guariglia DA, et al. Evaluation of the Omron MX3 Plus monitor for blood pressure measurement in adolescents. Eur J Pediatr. 2009;168(11):1349_ 1354; doi: 10.1007/s00431-009-0936-x.

14. Flynn JT, Kaelber DC, Baker-Smith CM, Blowey D, Carroll AE, Daniels SR, et al. Clinical practice guideline for screening and management of high blood pressure in children and adolescents. Pediatrics. 2017;140(3): e20171904; doi: 10.1542/peds.2017-1904.

15. Burns RD, Hannon JC, Brusseau TA, Eisenman PA, Saint-Maurice PF, Welk GJ, et al. Cross-validation of aerobic capacity prediction models in adolescents. Pediatr Exerc Sci. 2015;27(3):404-411; doi: 10.1123/ pes.2014-0175.

16. Brazilian Market Research Association. Brazilian economic classification criteria [in Portuguese]. São Paulo: ABEP; 2011. 
17. Richardson JTE. Eta squared and partial eta squared as measures of effect size in educational research. Educ Res Rev. 2011;6(2):135-147; doi: 10.1016/j.edurev.2010. 12.001 .

18. Klein M, Fröhlich M, Pieter A, Emrich E. Socio-economic status and motor performance of children and adolescents. Eur J Sport Sci. 2016;16(2):229-236; doi: 10.1080/17461391.2014.1001876.

19. Högström G, Nordström A, Nordström P. High aerobic fitness in late adolescence is associated with a reduced risk of myocardial infarction later in life: a nationwide cohort study in men. Eur Heart J. 2014;35(44):31333140; doi: 10.1093/eurheartj/eht527.

20. Cook NR, Cohen J, Hebert PR, Taylor JO, Hennekens $\mathrm{CH}$. Implications of small reductions in diastolic blood pressure for primary prevention. Arch Intern Med. 1995;155(7):701-709; doi: 10.1001/archinte.1995. 00430070053006.

21. Lewington S, Clarke R, Qizilbash N, Peto R, Collins R, Prospective Studies Collaboration. Age-specific relevance of usual blood pressure to vascular mortality: a meta-analysis of individual data for one million adults in 61 prospective studies. Lancet. 2002;360(9349): 1903-1913; doi: 10.1016/s0140-6736(02)11911-8.

22. Hoekstra T, Boreham CA, Murray LJ, Twisk JWR. Associations between aerobic and muscular fitness and cardiovascular disease risk: the Northern Ireland Young Hearts study. J Phys Act Health. 2008;5(6):815829; doi: 10.1123/jpah.5.6.815.

23. Eisenmann JC, Welk GJ, Ihmels M, Dollman J. Fatness, fitness, and cardiovascular disease risk factors in children and adolescents. Med Sci Sports Exerc. 2007; 39(8):1251-1256; doi: 10.1249/MSS.0b013e318064c8b0.

24. Campbell PT, Katzmarzyk PT, Malina RM, Rao DC, Pérusse L, Bouchard C. Prediction of physical activity and physical work capacity (PWC150) in young adulthood from childhood and adolescence with consideration of parental measures. Am J Hum Biol. 2001;13(2): 190-196; doi: 10.1002/1520-6300(200102/03)13:2< 190::AID-AJHB1028>3.0.CO;2-N

25. Kemper HC, de Vente W, van Mechelen W, Twisk JW. Adolescent motor skill and performance: is physical activity in adolescence related to adult physical fitness? Am J Hum Biol. 2001;13(2):180-189; doi: 10.1002/ 1520-6300(200102/03)13:2<180::AID-AJHB1027 $>3.0 . \mathrm{CO} ; 2-\mathrm{R}$.

26. Eisenmann JC, Wickel EE, Welk GJ, Blair SN. Relationship between adolescent fitness and fatness and cardiovascular disease risk factors in adulthood: the Aerobics Center Longitudinal Study (ACLS). Am Heart J. 2005;149(1):46-53; doi: 10.1016/j.ahj.2004.07.016.

27. Laurson KR, Welk GJ, Marton O, Kaj M, Csányi T. Agreement and diagnostic performance of FITNESSGRAM $^{\circledR}$, International Obesity Task Force, and Hungarian national BMI standards. Res Q Exerc Sport. 2015; 86(Suppl. 1):S21-S28; doi: 10.1080/02701367.2015. 1042786.
28. Franks PW, Hanson RL, Knowler WC, Sievers ML, Bennett PH, Looker HC. Childhood obesity, other cardiovascular risk factors, and premature death. N Engl J Med. 2010;362(6):485-493; doi: 10.1056/NEJMoa 0904130.

29. Parker ED, Sinaiko AR, Kharbanda EO, Margolis KL, Daley MF, Trower NK, et al. Change in weight status and development of hypertension. Pediatrics. 2016;137(3): e20151662; doi: 10.1542/peds.2015-1662.

30. Prentice AM, Jebb SA. Beyond body mass index. Obes Rev. 2001;2(3):141-147; doi: 10.1046/j.1467-789x.2001. 00031.x. 